

Working Paper no. 83

\title{
I nequality of Opportunity in Secondary School Enrolment in Italy, Germany and the Netherlands
}

\author{
Dalit Contini, Andrea Scagni \\ Università di Torino
}




\title{
Inequality of Opportunity in Secondary School Enrolment in Italy, Germany and the Netherlands
}

\author{
Dalit Contini, Andrea Scagni \\ University of Torino
}

\begin{abstract}
Aim of this work is to evaluate the overall effect of social origins on secondary school track enrolment in Italy, Germany and Netherlands, allowing for consistent cross country comparisons. PISA 2003 is employed. Track choices are assumed to depend on student's ability and social origins; since proficiency before tracking is not observed, ability is not kept under control. Nonetheless, the unconditional social background effect is the quantity of main substantive interest because it represents the total effect of social origins on school choices. Yet, since regression coefficients in logit models are biased even with independent unobserved heterogeneity, comparison across countries are difficult; the average sample derivative of the response probability is employed instead and it is showed to be a valid alternative measure of the total social origins effect. The following issue is also addressed: social origins inequality in secondary school choices may be affected by access restrictions policies, at work in some countries, where enrolment into the more prestigious tracks is subject to binding school recommendations or ability tests. First, we propose a simple theoretical model and we derive that the policy is expected to lower the effect of social origins conditional on ability, although the impact on the total effect can either decrease or increase. Second, by exploiting the institutional differences across German Länder with respect to enrolment policies, we carry out a preliminary empirical analysis within Germany. The main empirical findings are: (i) the total effect of social origins on track choice is weaker in the Netherlands and stronger in Germany, with Italy in between; (ii) within Germany, access restriction seem to weaken the parental background effect.
\end{abstract}

Keywords: inequality of opportunity, school tracks, access restrictions, unobserved heterogeneity, logistic regression, 


\section{Introduction}

The association between social origin and educational attainment has been the object of a large body of comparative research; despite the educational expansion process that has taken place in the last decades, inequality has not narrowed much (Breen and Jonsson, 2005; Buchmann, 2003; Shavit and Blossfeld, 1993). Inequality is also evaluated with respect to the level of competencies reached at a given level of schooling. The development of international surveys such as the PISA-Programme for International Student Assessment carried out by OECD to evaluate how students near the end of compulsory education have acquired "some of the knowledge and skills that are essential for full participation in society" (OECD, 2005) highlights that in most countries competencies are greatly dependent on family background. Equity and efficiency are not conflicting aims, however, as some of the countries with the lower social origin performance differentials are placed at the highest ranks with respect to average scores. Given these findings, equality of opportunity in education has become as an explicit target in the international educational policy agenda.

Educational systems vary with respect to how schooling careers are differentiated after a first stage common to all pupils; in many countries this translates into an set of alternative types of secondary schools, identifying distinct school tracks. In tracked systems the level and kind of competencies change markedly among school types; moreover in many countries access to tertiary education is restricted to a track specifically conceived to prepare for university studies, often called the academic track (or lyceum). The choice of the track is thus an important step in the student's life, as it is likely to shape his future educational career and consequently, employment prospects. The extent to which this choice is affected by parental background has been the object of research in different countries (for Germany: Dustmann, 2001 and Schnepf, 2002; for Italy: Cappellari, 2004 and Checchi and Flabbi, 2006). Not surprisingly, the evidence is that social background plays a major role in shaping track 
choices. Checchi and Flabbi (2007) compare Italy and Germany in this respect; we will come back shortly to their findings.

Class differentials in educational attainment are related in the literature to two distinct mechanisms: primary and secondary effects (Boudon, 1974, Erikson and Goldthorpe, 2002). Primary effects refer to the influence of social origin on ability early in children's educational careers. Secondary effects operate through the choices that families make within the educational system, given ability. Assuming that families wish to avoid downward mobility, the rational action approach (Goldthorpe, 1996; Breen and Goldthorpe, 1997) provides a theoretical explanation for the evidence that, conditional on performance, school choices vary across social background. The evaluation of the relative importance of primary and secondary effects is the aim of a growing body of literature (for example, Erikson et al 2005, Jackson et al 2007), in particular at the moment of secondary school choice, providing empirical evidence of the relevance of secondary effects in the creation of class differentials in educational attainment. However, since the analysis are carried out on national level data, comparing the results across countries is not an easy task.

A recent body of research carried out mainly by economists (Hanushek and Woessman, 2005; Woessman, 2007; Brunello and Checchi, 2007) tackles the issue of the impact evaluation of specific institutional features on inequality of opportunity, by exploiting the cross-national variability available in international surveys such as PISA, TIMMS and IALS ${ }^{1}$. The main object of investigation is the effect of the age of tracking on school performance or later educational attainment; overall, there is strong evidence that inequality is enhanced with early tracking. Similarly, Pfeffer (2008) examining the overall degree of inequality in educational attainment in the last decades in many countries, relates inequality to institutional features of the schooling systems, drawing the conclusion that more stratified systems exhibit on average a lower intergenerational educational mobility.

Aim of the present work is to compare the total effect of social origins on secondary 
school track enrolment in Italy, Germany and the Netherlands. The empirical analysis is based on data from PISA 2003. Although PISA has not been designed for this purpose, its major advantage with respect to national data archives is that variables (in particular variables measuring social background) and the sampling scheme are common, favouring crosscountry comparability. Moreover, PISA represents a valid alternative to other data sources if no longitudinal data specifically designed to record youth schooling and working careers is available. This is the case for Italy, where the only survey specifically designed for investigating schooling careers is a cross-sectional survey on secondary school leavers ${ }^{2}$, a sample obviously affected by a strong non-random selection; since sampling occurs at age 15 , selection bias due to school drop-out is weaker with PISA ${ }^{3}$.

The countries under study differ with respect to many institutional features. First, tracking occurs at different ages: at 14 in Italy, at 12 in the Netherlands, at 10 in Germany. Second, while in Italy there is practically full freedom of choice, in some German Länder and in Netherlands enrolment to the more prestigious tracks, lyceum in particular, is limited by binding school's recommendations or proficiency tests. As explained later, the role of access restrictions on inequality of opportunity in secondary school choices will be object of specific attention in the present work. Countries school designs differ in many aspects and it is difficult to find a comparable classification among academic, technical and vocational schools; moreover the German education system is Länder-based, so students face a different set of available options from state to state. Hence, we focus on the more clear-cut distinction between the academic track (lyceum) and all other tracks; this is common in the literature (Erikson et al, 2005) and retains a close relation to tertiary education decisions.

The analysis is carried out by referring to a simple model for the ability development process, where social background is assumed to influence ability at each stage of the individuals' schooling life: the rationale is that high status parents are more likely to sustain and motivate school work and provide a stimulating environment throughout their offspring 
growth. Coherently with the literature, our model relates secondary school track choices to the student's ability and to social origins. Since a measure of performance before tracking is not provided, ability is not kept under control and primary and secondary effects are not disentangled. Nonetheless, wishing to provide a synthetic measure of inequality across countries, the unconditional social background effect is the quantity of main substantive interest because it represents the total effect of social origins on secondary school choices.

The interest in comparing Italy and Germany stems from the following reasons. First, Germany is an interesting reference point as its early tracking system has been sharply criticized because it is believed to enhance parents' social background influence on future educational attainment (Dustmann, 2001; Schnepf, 2002; Sinn, 2006). Second, Checchi and Flabbi (2007) - who also compare Italy and Germany with respect to the effect of social background on secondary school choices with PISA - claim instead that students' sorting into tracks is less related to parental background and more to individual ability in Germany than Italy. They also claim that the supposedly weaker social origin effect could be due to the fact that some German Länder enforce stricter performance-based transition processes from primary to secondary school, while in Italy there is freedom of choice ${ }^{4}$. As we will argue more thoroughly in Section 4, we question this result for two reasons: (i) The measure they employ for the comparison is the effect of social background conditional on ability. We think instead that the relevant measure for assessing the effect of social origins should be the unconditional effect, as the former represents secondary effects only, while the latter the total effect; (ii) With the aim to assess the conditional effect, PISA scores are used to proxy ability $^{5}$ : the flaw is that these scores refer to a time well after that of choice and thus are endogenous. A simulation exercise has been developed (and presented in the Appendix) to show that this practice can lead to severely biased estimates. In this light, we think that the comparison between Italy and Germany should be re-evaluated.

On the other hand, Checchi and Flabbi's idea that access restrictions could reduce the 
impact of social background on school choices is stimulating and we think it should be given specific attention. To our knowledge, there are no studies addressing this issue. Our work is an attempt to fill this gap. First, we develop a simple theoretical model to shed light on how access restrictions should influence the effect of social status on secondary school enrolment; we show that restrictions should lower the effect of social origins conditional on ability, but the impact on the total effect can go in either directions. Second, by exploiting the institutional differences across the German Länder with respect to enrolment policies, we carry out a preliminary empirical analysis within Germany. Under the (strong) assumption that the model is well specified, the policy impact on inequality of opportunity can be assessed simply by comparing the social background effect between states with and without restrictions.

The main empirical findings are that the total effect of social origins on track choice is weaker in the Netherlands and stronger in Germany, with Italy in between; and that within Germany, parental background appears to be less important where access is regulated by ability assessments. As our theoretical model suggests, however, the latter should not be considered a general result. Note that ethical arguments against restrictions, related to the concern that some individuals are not given the chance to enter the academic track - even if there is the awareness that ability assessment may be flawed by measurement error, and that children develop skills at different stages of their lives and may catch up after sorting has taken place - are not addressed here.

A statistical problem frequently overlooked in the empirical literature is also addressed. Logistic model regression coefficients - functionally related to odd-ratios, and commonly employed in the literature to measure the association between a binary variable and another variable - are estimable up to arbitrary identification restrictions on the error variance, and with independent unobserved heterogeneity are biased towards zero. Although ability is not independent of social background, we can still refer to the independent heterogeneity 
framework if the total effect is the parameter of interest. Since the bias depends on the variance of the omitted variable, comparing regression coefficients estimates across countries can lead to misleading results. On the other hand, by extending Cramer (2005) simulation study, we show that the average sample derivative of the response probability with respect to social background is substantially unbiased even when ability is unobserved.

The paper is organized as follows. In Section 2 we briefly review the institutional features of the educational systems in the countries of interest. Some evidence on stratification in secondary schools is presented in Section 3. Section 4 introduces the model for secondary school choices and the ability development process. The statistical problems arising when comparing explanatory variables effects across samples with unobserved heterogeneity are discussed in Section 5. In Section 6 we develop a simple theoretical model for the effect of access restrictions on equality of opportunity. The empirical analysis is presented in Section

7. Conclusions follow in Section 8. The simulation study is described in the Appendix.

\section{Educational Systems}

\subsection{Italy}

Compulsory education goes from age 6 to 15. There are five years of primary school and three years of comprehensive lower secondary education. At 14 students choose their upper secondary school between many different programmes. The academic track lasts five years and includes different types of lyceum: classical, scientific, linguistic, artistic. The sociopedagogic lyceum prepares for the primary teacher career. Although further university education is now required, until a few years ago the school gave direct access to the profession; for this reason it is not fully perceived as an academic programme ${ }^{6}$. The technical and vocational tracks (lasting respectively five and three years) lead directly to a professional qualification. There are no special admission requirements, such as ability tests or marks, to 
enter the different tracks. After five years of schooling (with two integrative years for vocational schools), all tracks give access to university (Eurydice, 2006b). In practice, only few students from the vocational track enter tertiary education.

\subsection{Netherlands}

Primary education lasts 8 years, from age 4-5 to 12-13 (most students start at 4). Schooling is compulsory until age 16, with one more year of part-time or full-time education (Eurydice, 2006c). At twelve pupils are divided into three main tracks. The academic $V W O$ prepares for university in six years, $H A V O$ provides higher general education for five years giving access to higher professional education and $V M B O$ is a vocational school, divided into different pathways lasting four years and giving access to apprenticeship. Students' suitability for the different tracks is assessed by a primary school leavers attainment test (CITO $)^{7}$; parents may express preferences, but the secondary school board has the final decision. Lower secondary education (the first three years of $V W O$ and $H A V O$ or the whole $V M B O$ course) must be completed in five-six years. If students fail twice in the same grade they must change track. $V M B O$ or $H A V O$ leaving certificates give access to the higher level tracks only with a good curriculum. A noticeable feature of the Dutch system is the diffusion of publicly financed private schools, attended by over $70 \%$ of all students (Eurydice, 2003).

\subsection{Germany}

The German school system is rather heterogeneous, since the Länder are responsible for education. Tracking occurs at age 10 in most states, with the exception of the states of Berlin and Brandenburg, where it takes place at age 12 (Woessmann 2007). Institutional differences regard also school track types and admission requirements. Compulsory education is from age 6 to 18, with at least 9 full-time schooling years. Primary school lasts four years (age 610); the school board generally gives recommendation for the transition to secondary school, 
but while in some Länder families are still free to choose $^{8}$, in others enrolment is conditional on binding school recommendations ${ }^{9}$. During secondary school each grade can be repeated only once: a second failure in the same or the following grade compels a change to a lower level track. In most Länder there are three tracks: Gymnasium (academic), lasting nine years (recently being reduced to eight) for a total 12 years of schooling, Realschule (professional, six years), and Hauptschule (vocational, five or six years). The first gives access to university, the others to different professional or vocational education and apprenticeship, usually combining job training and school lessons. After Hauptschule, the Realschule leaving certificate can be obtained as well, conditional on the achievement level. Similar rules apply for the transition from Realschule to Gymnasium. In some Länder the Realschule and Hauptschule programmes are provided in the same school ${ }^{10}$, with distinct school leaving certificates (Eurydice, 2006a). In many states there are also comprehensive schools (Integrierte Gesamtschule or Kooperative Gesamtschule) sometimes attracting more students than the traditional tracks. Thus every Länder has its very own combination of school types and admission rules.

\section{Stratification in schools. Evidence from PISA}

PISA is an international survey of the skills of 15 year olds promoted every three years by OECD. Each survey covers different topics: mathematics, reading comprehension, science and problem solving. The main topic for PISA 2003 is mathematics: tests evaluate how well students can recognize, formulate and tackle mathematical problems in real life contexts. Detailed information on family background is recorded, and a specific index measured on a continuous scale - ESCS (index of Economic, Social and Cultural Status, see Section 7) - is provided.

PISA reveals wide differences in countries' skill profiles (OECD, 2004). Average scores in 
math tests are reported in Table 1, column (5): Italy is placed at the lowest ranks in the $\mathrm{OECD}^{11}$, Germany is around the average, while the Netherlands is considered a well performing country.

Simple measures of stratification in school can be computed with PISA because approximately 30 students are chosen within each school. A measure of social stratification is given by the ratio of the variance between schools to the total variance of ESCS. Table 1, column (1) reports such ratio for selected countries. Generally, early tracked systems rank in the top half of the list (Hungary, Austria, Italy, Germany); Netherlands is an exception, exhibiting a much smaller value, close to that of late tracking school systems. Similar results hold for the percentage of variance between tracks (instead of single schools), reported in column (2). A measure of performance stratification, provided by an analysis of variance of math PISA scores, is reported in columns 3-4. Netherlands places first in the OECD area, followed by Germany. Variance between single schools is over $60 \%$ of the total variance and over $50 \%$ between school tracks for both countries. The value for Italy is somewhat smaller at the single school level, dropping to less than $25 \%$ for tracks.

The differences across schools and school tracks should be interpreted cautiously, because PISA scores measure ability after choice. Since skills keep on developing during secondary school, with different rates across individuals and tracks, the data does not tell us how well students are tracked according to their ability. Cross-country comparisons are difficult also because tracking occurs at different ages. Nevertheless, these numbers suggest that:

- in the Netherlands students are well divided by ability into tracks and these differences reflect social differences only to a small extent;

- in Germany school sorting also seems to be highly related to ability (although the earlier tracking makes the issue of endogeneity more severe), but social stratification in schools is much stronger than in the Netherlands; 
- social differences among schools are also deep in Italy; since score variability is large across schools but not across tracks, differences in ability among students of different schools are only partially related to differences in the curricula.

Table 1. Social stratification in schools. Analysis of variance between schools and between school types for ESCS and PISA mathematic scores. Selected countries

\begin{tabular}{|c|c|c|c|c|c|c|}
\hline \multicolumn{3}{|c|}{ ESCS } & \multicolumn{4}{|c|}{ PISA math scores } \\
\hline Country & $\begin{array}{c}(1) \\
\text { Between } \\
\text { Schools } \eta^{2} \\
\end{array}$ & $\begin{array}{c}(2) \\
\text { Between } \\
\text { School-types } \eta^{2}\end{array}$ & Country & $\begin{array}{c}\text { (3) } \\
\text { Between } \\
\text { Schools } \eta^{2}\end{array}$ & $\begin{array}{c}(4) \\
\text { Between } \\
\text { School-types } \eta^{2} \\
\end{array}$ & $\begin{array}{l}5) \\
\text { Mean } \\
\text { score } \\
\end{array}$ \\
\hline Hungary & 0.449 & 0.315 & Netherlands & 0.659 & 0.556 & 538 \\
\hline Austria & 0.343 & 0.256 & Germany & 0.629 & 0.511 & 503 \\
\hline Italy & 0.343 & 0.216 & Hungary & 0.602 & 0.413 & 490 \\
\hline Germany & 0.332 & 0.232 & Belgium & 0.575 & 0.545 & 529 \\
\hline Belgium & 0.331 & 0.252 & Italy & 0.569 & 0.246 & 466 \\
\hline France & 0.315 & 0.159 & Austria & 0.563 & 0.411 & 506 \\
\hline Spain & 0.305 & * & France & 0.520 & 0.450 & 511 \\
\hline United States & 0.272 & $*$ & United States & 0.310 & $*$ & 483 \\
\hline Netherlands & 0.257 & 0.159 & Spain & 0.272 & $*$ & 485 \\
\hline Finland & 0.141 & $*$ & Finland & 0.083 & $*$ & 544 \\
\hline
\end{tabular}

$\eta^{2}$ is the ratio of the variance between schools or school-types over the total variance of ESCS or PISA scores

* Systems with no tracking before age 15

\section{The model}

"Human capital accumulation is a dynamic process. The skills acquired in one stage of the life cycle affect both the initial conditions and the technology of learning at the next stage." (Carneiro and Heckman, 2003, pg. 6). In this perspective we propose a simple model for the ability development process (see Figure 1), where the factors affecting ability include individual endowments (innate ability) and family endowments (social origins). Since the different tracks can provide a different "added value", ability after tracking is also allowed to depend on the school type. Although not explicit in the figure, institutional features obviously enter the picture, affecting the whole process in potentially complex ways.

The issue we address here is how strongly social background affects secondary school choices, assuming that: 
i. there is a latent unobservable individual "innate ability" which might be correlated or not correlated with individual's social background;

ii. individual ability ${ }^{12}$ before school choice ( "previous ability") depends on innate ability and social origins;

iii. the choice of the secondary school track depends on previous ability and social origins (although track and innate ability are independent given previous ability).

Consequently, social background can affect school-choice in two distinct ways:

- Direct effect: given the level of ability, individuals from the advantaged social backgrounds are more likely to enter the academic track (because of higher incentives and aspirations, lower opportunity costs, higher probability of success);

- Indirect effect: higher status children reach on average higher levels of ability at the end of primary or lower secondary school (as they are generally exposed to more intellectual stimulation, receive more parental motivation and support for schoolwork); being more skilled, they are expected to prefer the academic track.

Notice that direct and indirect effects are strictly related to primary and secondary effects. The indirect effect depends on the relation between social background and early ability, and on the relation between early ability and school track; the latter is affected by the way preferences for a particular track are affected by ability, but also on admission policies. If enrolment is conditional on achievement (as occurs in Netherlands and some German Länder) only the higher performing students are admitted to the academic track. Such mechanism has not been taken into explicit consideration in the literature on primary and secondary effects, but it has a relevance in shaping class differentials and should be acknowledged if research focuses on policy evaluation: we will discuss this point in Section 6.

Data on student's ability before secondary school choice is needed to disentangle direct and indirect effects. As Breen et al. (2005) point out, the different effects of social origin on 
educational attainment cannot be disentangled without longitudinal data. In this context, surveys like PISA with a longitudinal design would allow to relate the whole ability development process sketched in Figure 1 to social origins.

Nonetheless, under the assumptions sketched above, when modelling school choice without controlling for ability the regression coefficient of $S B$ is a relevant measure for comparing the strength of inequality of opportunity among social strata in different countries, as it represents the total effect of social origins on school track, given by the direct plus the indirect effect.

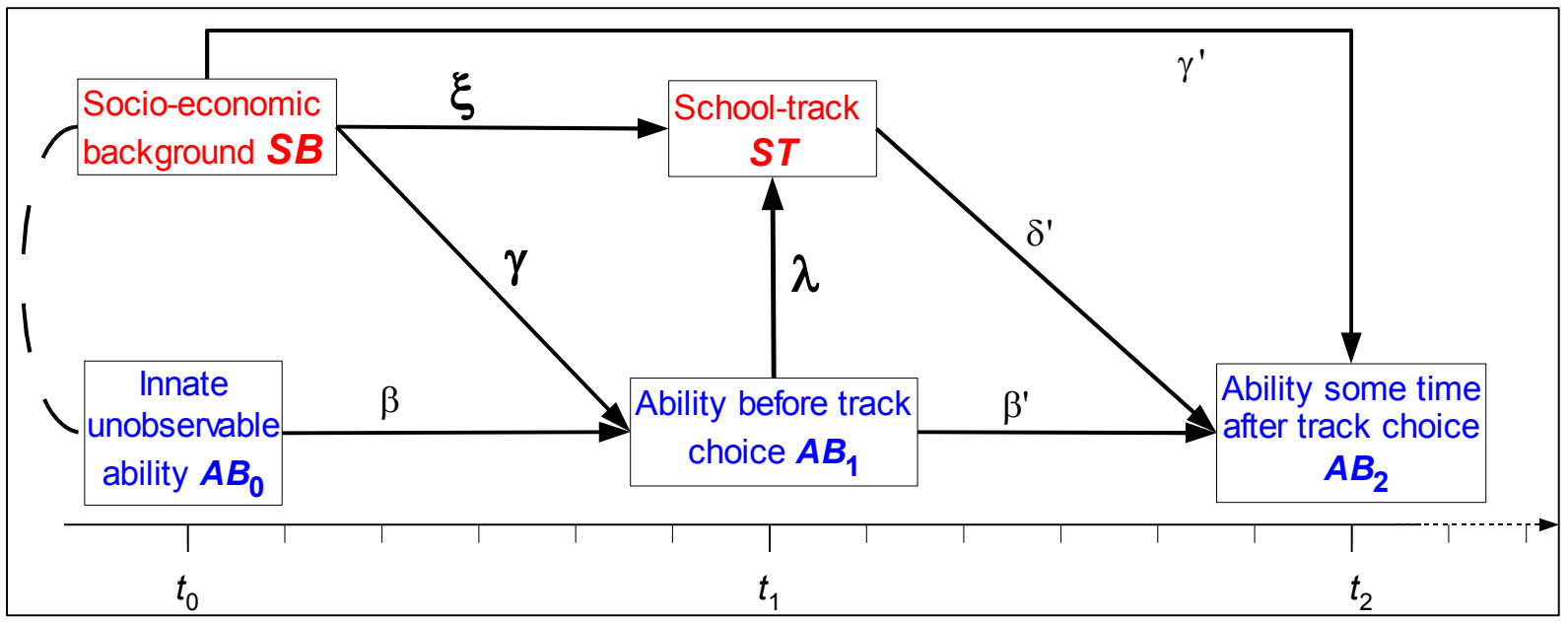

Figure 1. Modeling secondary school choices and the ability development process

Let $A B_{t}$ represent ability at time $t$. Consider the time of birth $t=0$, a time $t=1$ before secondary school choice and the time $t=2$ after track choice. Thus: $A B_{0}$ is the unobservable innate ability; $A B_{1}$ is previous ability (potentially observable, but here unobserved); $A B_{2}$ is ability some time after tracking (measured for example by the PISA score).

$S B$ is a measure of social background and $T C$ a binary indicator of academic track choice. Formalizing the model in Figure 1, we assume that individual ability develops as follows:

$$
A B_{1 i}=\alpha+\beta A B_{0 i}+\gamma S B_{i}+u_{i}
$$




$$
\begin{aligned}
& U_{i}=\mu+\lambda A B_{1 i}+\xi S B_{i}+\varepsilon_{i} \\
& T C_{i}= \begin{cases}1 & \text { if } U_{i}>0 \\
0 & \text { if } U_{i} \leq 0\end{cases} \\
& A B_{2 i}=\alpha^{\prime}+\beta^{\prime} A B_{1 i}+\gamma^{\prime} S B_{i}+\delta^{\prime} T C_{i}+u^{\prime}{ }_{i}
\end{aligned}
$$

$U$ is a latent variable related to the utility of enrolling in the alternative tracks ${ }^{13}$, and $T C$ its observed counterpart. The errors for each equation are mutually independent and independent from the explanatory variables included in their own equation. All regression coefficients in the model are likely to be positive. If the error $\varepsilon_{i}$ has a standard logistic distribution, equations (2a)-(2b) give rise to the well known expression for the logit model:

$$
\ln \left(\frac{\operatorname{Pr}\left[T C_{i}=1\right]}{1-\operatorname{Pr}\left[T C_{i}=1\right]}\right)=\mu+\lambda A B_{1 i}+\xi S B_{i}
$$

Equation (3) is based on the assumption that ability after tracking is directly affected by previous ability, school-type and social background. This equation - not directly relevant for assessing inequality in school choices - is employed to evaluate with simulations the strategy adopted by Checchi and Flabbi $(2006,2007)$ of using the PISA score as a proxy for ability before tracking. The problem is that PISA scores refer to a time well after that of school choice (1 year after for Italy, 3 for Netherlands, 5 for Germany), thus they are (highly) endogenous. The simulation exercise, described in the Appendix, shows that both the direct effect of social background on school track $\xi$ and the ability coefficient $\lambda$ can be severely biased.

If ability is not included as an explanatory variable, the equation for latent $U$ becomes:

$$
\begin{aligned}
U_{i}= & \mu+\lambda\left(\alpha+\beta A B_{0 i}+\gamma S B_{i}+u_{i}\right)+\xi S B_{i}+\varepsilon_{i} \\
& =(\mu+\lambda \alpha)+(\lambda \gamma+\xi) S B_{i}+\left(\lambda \beta A B_{0 i}+\lambda u_{i}+\varepsilon_{i}\right)
\end{aligned}
$$

The coefficient of $S B$ is now $(\lambda \gamma+\xi)$, the total effect of social background on the probability to enrol in higher track schools; it includes the direct effect $\xi$ plus the indirect effect $\lambda \gamma$. As 
we have argued before, this unconditional effect is the quantity of main interest. The direct effects of ability and social background $\lambda$ and $\xi$ are instead not separately identified.

Notice that if innate ability and social background are independent, class differentials may be caused by different "nurture" effects and by the different rational behaviour among social classes. If instead innate ability and social background are correlated, the total effect also includes "nature" effects ${ }^{14}$. Letting $A B_{0}=a+\theta S B+w$, the total effect in this case is equal to $(\gamma \lambda+\xi+\lambda \beta \theta)$

The consequences of neglecting ability in binary response models for school track choice are discussed in the next Section.

\section{Assessing the total effect of social background}

Assessing the effect of explanatory variables on the response variable is less straightforward in binary response models than it is in linear models, in particular with neglected heterogeneity. This circumstance is relevant in our context because - wishing to evaluate the unconditional effect of social background with respect to the distribution of ability - we omit the explanatory variable "previous ability" from the estimated model.

\subsection{General discussion}

Let $Y$ be a binary response variable, $\boldsymbol{X}$ the $K$-vector of explanatory variables and $\boldsymbol{\beta}$ the $K$ vector of coefficients. Perhaps the most common way to interpret the effect of explanatory variables is to refer to the exponential of each coefficient, which represents the odds-ratio:

$$
e^{\beta_{k}}=\frac{\frac{\operatorname{Pr}\left(Y=1 \mid X_{k}=c+1, X_{-k}\right)}{1-\operatorname{Pr}\left(Y=1 \mid X_{k}=c+1, X_{-k}\right)}}{\frac{\operatorname{Pr}\left(Y=1 \mid X_{k}=c, X_{-k}\right)}{1-\operatorname{Pr}\left(Y=1 \mid X_{k}=c, X_{-k}\right)}}
$$

where $X_{k}$ is the explanatory variable of interest and $X_{-k}$ is the vector of the remaining 
explanatory variables. The advantage is that this ratio in invariant with respect to $c$. On the other hand, the odds-ratio has the disadvantage of not capturing the difference between changes in the response probability where the curve is almost flat and where it is steeper, neither it recognizes that the slope of the curve varies, given $x$, with the value of the constant and of the other explanatory variables ( $w$ in Figure 2).

For this reason, alternative measures based on the absolute change of the response probability are now widely employed. Measures based on the slope of the probability curve, i.e., the partial derivative of $\operatorname{Pr}(Y=1 \mid X)$ with respect to the explanatory variable $X_{k}$. have been proposed in the econometric literature for continuos variables ${ }^{15}$ (e.g. Long, 1997; Wooldridge, 2002). One of them is the slope of the response probability at the average value of the explanatory variables vector, which can be thought as a "representative" individual; we call it the effect at the sample average (ESA):

$$
E S A=\frac{\partial \hat{\operatorname{Pr}}(Y=1 \mid \overline{\boldsymbol{x}})}{\partial x_{k}}
$$

Another measure is the average slope over all the sample units ASE (average sample effect):

$$
A S E=\text { sample mean } \frac{\partial \hat{\operatorname{Pr}}(Y=1 \mid \boldsymbol{x})}{\partial x_{k}}=\frac{1}{n} \sum_{i=1}^{n} \frac{\partial \hat{\operatorname{Pr}}\left(Y_{i}=1 \mid \boldsymbol{x}\right)}{\partial x_{k}}
$$

For a given $\beta_{k}$, the $A S E$ changes according to the actual location of the explanatory variables in the sample. Suppose we wish to compare the effect of $X_{k}$ across countries. Consider countries A and $\mathrm{B}$, with the same value of $\beta_{k}$; if explanatory variables in country A are located where the curve is almost flat while in country B they are in the steep part of the curve then, when $X_{k}$ changes, the response probability changes more in B than in A. Coherently, $A S E_{A}<A S E_{B}$.

It can be shown that for the logit model: 


$$
A S E=\frac{1}{n} \sum_{i=1}^{n} \hat{\operatorname{Pr}}\left(y_{i}=1 \mid x\right)\left(1-\hat{\operatorname{Pr}}\left(y_{i}=1 \mid x\right)\right) \hat{\beta}_{k}
$$

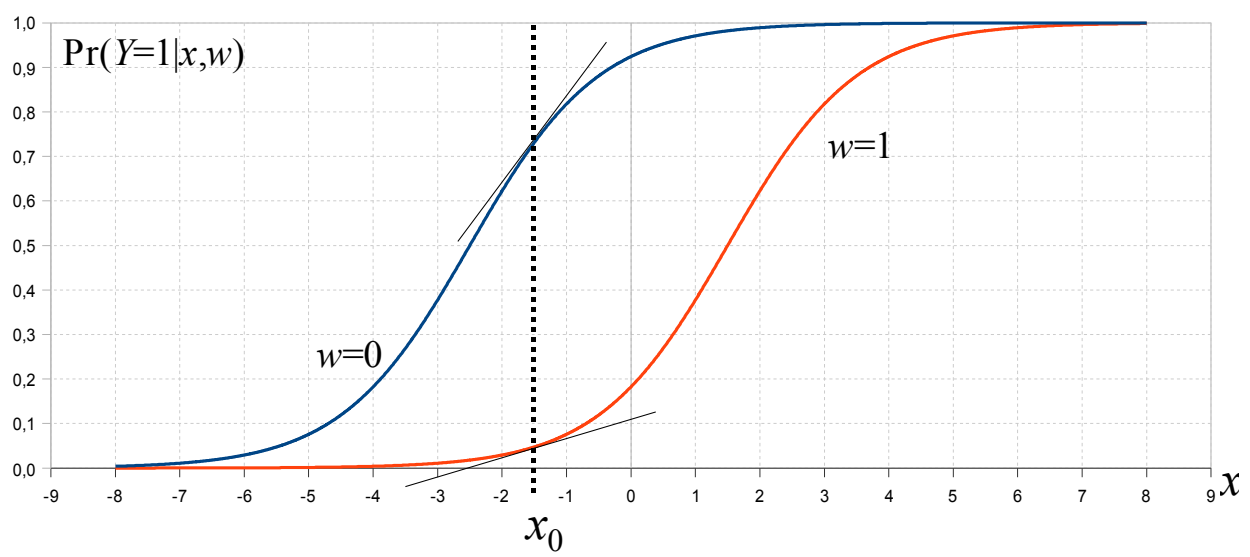

Figure 2. Slope of the logistic function at different values of explanatory variables

The interpretation problems of regression coefficient become more severe with neglected heterogeneity. While the omission of an orthogonal regressor (i.e., uncorrelated with the included explanatory variables) does not affect OLS estimates in linear models, it will bias $\beta$ coefficients towards zero when standard estimation methods for binary choice models are employed (Cramer, 2005; Wooldridge, 2002). This occurs because arbitrary assumptions on the error variance are necessary to identify regression coefficients. When an orthogonal explanatory variable $w$ is omitted, the estimated parameter is no longer the original $\beta_{k}$, but the smaller value:

$$
\beta_{k}\left(\frac{\sigma_{\varepsilon}^{2}}{\sigma_{\varepsilon}^{2}+\left(\beta_{w}\right)^{2} \operatorname{Var}(w)}\right)
$$

where $\beta_{w}$ is the regression coefficient of the neglected variable. If $\operatorname{Var}(w)$ or $\beta_{w}$ vary across countries, comparing the $\hat{\beta}$ 's can be meaningless, because the estimates in some contexts are more strongly biased than in others. Suppose we find $\hat{\beta}_{k A}<\hat{\beta}_{k B}$. Does this occur because the effect of the independent variable is stronger in environment B or because the coefficient is 
more heavily underestimated in A?

The $A S E$ has the advantage that it is not affected by independent neglected heterogeneity. Wooldridge (2002, pg. 471) proves the result for the probit model when the omitted variable has a normal distribution. The behaviour of $A S E$ is more difficult to derive analytically for the logit model; Cramer (2005) develops a simple simulation study finding that $A S E$ is hardly affected also in logit models. A first intuition behind this result is that neglected heterogeneity attenuates the differences of the estimated $\operatorname{Pr}(Y=1 \mid \boldsymbol{x})$ across units, which get closer to the average probability. From equation (6), since $\operatorname{Pr}(Y=1 \mid \boldsymbol{x})[1-\operatorname{Pr}(Y=1 \mid \boldsymbol{x})]$ is maximum when $\operatorname{Pr}(Y=1 \mid \boldsymbol{x})=0.5$, this product is overestimated with unobserved heterogeneity; on the other hand, $\hat{\beta}$ is underestimated, thus the two effects compensate each other. The explanation provided by Wooldridge (2002) for probit models is also insightful: partial effects of $\operatorname{Pr}(Y=1 \mid X)$ can be employed because they are the average of the partial effects of $\operatorname{Pr}(Y=1 \mid \boldsymbol{X}, \boldsymbol{w})$ over the distribution of the omitted variable $w$.

\subsection{Back to our model}

We will now look at how these issues apply to the model in (1)-(4). Since previous ability $A B_{1}$ is correlated with social background $S B$, the results derived for the omission of an independent variable do not immediately apply to our case. As we have argued in Section 4, the omission of previous ability $A B_{1}$ implies that instead of the original full equation (2c) we refer to the reduced form $U_{i}=(\mu+\lambda \alpha)+(\lambda \gamma+\xi) S B_{i}+\left(\lambda \beta A B_{0 i}+\lambda u_{i}+\varepsilon_{i}\right)$. If innate ability $A B_{0}$ and $S B$ are independent, the coefficient of $S B$ represents the total effect $(\gamma \lambda+\xi)$ and the new error term is independent of $S B$; if $A B_{0}$ and $S B$ are linearly related, say $A B_{0}=a+\theta S B+\tau$, $U_{i}=(\mu+\lambda \alpha+\beta a)+(\lambda \beta \theta+\lambda \gamma+\xi) S B_{i}+\left(\lambda \beta \tau_{i}+\lambda u_{i}+\varepsilon_{i}\right) ;$ the social origins coefficient becomes $(\gamma \lambda+\xi+\lambda \beta \theta)$ (capturing nature and nurture effects), and the error is still independent of $S B$. In sum, if we acknowledge that what we are estimating is not the 
coefficient of $S B$ conditional on ability, but the total effect of $S B$ - which is actually what we are interested in - we can still refer to the independent neglected heterogeneity framework.

A consequence of the omission of ability is that the error term is now larger than the original error in (2a), thus, strictly speaking, when omitting ability the probability no longer follows a logistic distribution. Following Cramer, the total effect estimator is biased towards zero. In particular, the error depends on $\lambda$ (the effect of previous ability on track preferences), thus the countries where individual ability plays a greater role in shaping school choices should suffer from a larger relative bias. Hence the direct comparison of the social background coefficient across countries can lead to ambiguous results.

On the other hand, the corresponding $A S E$ should be nearly unbiased. Since the simulation exercise carried out by Cramer (2005) is based on a very simple model, we have implemented a simulation study based on model (1)-(4) in order to assess the behaviour of ASE and the magnitude of the regression coefficients bias in the present context. The results (shown in the Appendix) largely confirm that $A S E$ adequately captures the $S B$ total effect on school choices; the effect at the sample mean (ESA) appears instead to be highly sensitive to neglected heterogeneity.

\section{Access restrictions}

Purpose of this Section is to discuss from a theoretical perspective the effect of access restrictions based on ability assessments on inequality: we will show that the direct effect of social background on secondary school enrolment is reduced, while the total effect may either increase or decrease. A simple theoretical model is proposed. Let us distinguish between TC (standing for "track choice") which represents individual's preferences and EN representing actual enrolment; both are binary variables, taking value 1 for lyceum and 0 for the other tracks. Preferences are assumed to be driven by random utility (2a). Lyceum is the preferred 
track and thus $T C=1$ if $U>0$, while $T C=0$ otherwise.

When no access restrictions apply, enrolment and preferences overlap, i.e. $T C=E N$. On the other hand, with ability restrictions (assuming a very simple decision rule) students are accepted to lyceum only if $A B>a_{0}$. Enrolment is described by:

$$
E N=\left\{\begin{array}{cc}
1 & \text { if }(T C=1) \cap\left(A B>a_{0}\right) \\
0 & \text { otherwise }
\end{array}\right.
$$

We assume for simplicity that ability is perfectly assessed, although results do not change substantially if we allow for measurement error.

We now compare the effect of social background on secondary school enrolment with and without access restrictions. To simplify the notation, without loss of generality, a binary variable $S B$ taking value 1 for "high" status and 0 for "low" status has been employed.

Two relevant effects of social background on secondary school enrolment are considered; (i) the direct effect, measuring the net change of $P(E N=1 \mid A B, S B)$ due to an increase of $S B$, given ability; (ii) the total effect, which refers instead to the average with respect to the distribution of ability:

$$
P(E N=1 \mid S B)=\int_{A B} P(E N=1 \mid A B, S B) f(A B \mid S B) d A B
$$

Notice that the distribution of ability $f(A B)$ is allowed to depend on social background, reflecting the existence of primary effects.

We now show that, other thing being equal, the policy of restricting lyceum enrolment according to ability has the effect of lowering the direct effect of $\mathrm{SB}$, whereas the total effect of SB may either increase or decrease. Similar results also hold with independent measurement error. 


\section{Direct effect}

With no restrictions, preferences and actual enrolment coincide, thus:

$$
P(E N=1 \mid A B, S B)=P(T C=1 \mid A B, S B)=P(U>0 \mid A B, S B)=P(\varepsilon>-\mu-\lambda A B-\xi S B)
$$

A measure of the direct effect is:

$$
P(E N=1 \mid A B, S B=1)-P(E N=1 \mid A B, S B=0)=P(\varepsilon>-\mu-\lambda A B-\xi)-P(\varepsilon>-\mu-\lambda A B)
$$

On the other hand, with access restrictions,

$$
P(E N=1 \mid A B, S B)=P\left((T C=1) \cap A B>a_{0} \mid A B, S B\right)=\left\{\begin{array}{cl}
P(T C=1 \mid A B, S B) & \text { if } A B>a_{0} \\
0 & \text { if } A B<a_{0}
\end{array}\right.
$$

thus the direct effect is equal to the no restrictions case for the students passing the ability threshold $A B>a_{0}$, while it is 0 for lower performing students, as all of them, regardless of social status, are not admitted to lyceum. Thus, on average, the direct effect of social background on school enrolment decreases with access restrictions.

\section{$\underline{\text { Total effect }}$}

The total effect may be measured by:

$$
P(E N=1 \mid S B=1)-P(E N=1 \mid S B=0)
$$

With no restrictions it becomes:

$$
\int_{A B} P(\varepsilon>-\mu-\lambda A B-\xi) f(A B \mid S B=1) d A B-\int_{A B} P(\varepsilon>-\mu-\lambda A B) f(A B \mid S B=0) d A B
$$

while, when access depends on ability, it turns into:

$$
\int_{A B>a_{0}} P(\varepsilon>-\mu-\lambda A B-\xi) f(A B \mid S B=1) d A B-\int_{A B>a_{0}} P(\varepsilon>-\mu-\lambda A B) f(A B \mid S B=0) d A B
$$

It is not possible to assess a priori whether the total effect is higher with or without restrictions. This indeterminacy is shown in Figure 3 in the particular case of $\varepsilon=0$ (no substantial difference arises with a random component). The bell shaped curves are the ability density functions of the low and high social status. The straight lines are the utility functions, and depend on both ability and social background. The share of students of each social 
background level having a preference for lyceum is represented by the area under the ability density function corresponding to $U>0$. The corresponding share of those eventually enrolling into a lyceum is represented by the area where $U>0$ and $A B>a_{0}$.

Panel (a) depicts a case where high status students only are rejected, as all the low status having a preference for lyceum are above the ability threshold: in this situation the total effect of social background on school choices decreases with access restrictions. Panel (b) refers instead to a circumstance where the majority of the low status students who would choose lyceum are not admitted because they do not reach the ability threshold, while only a small proportion of the high status is rejected, giving rise to a larger total effect with respect to the no restrictions environment.

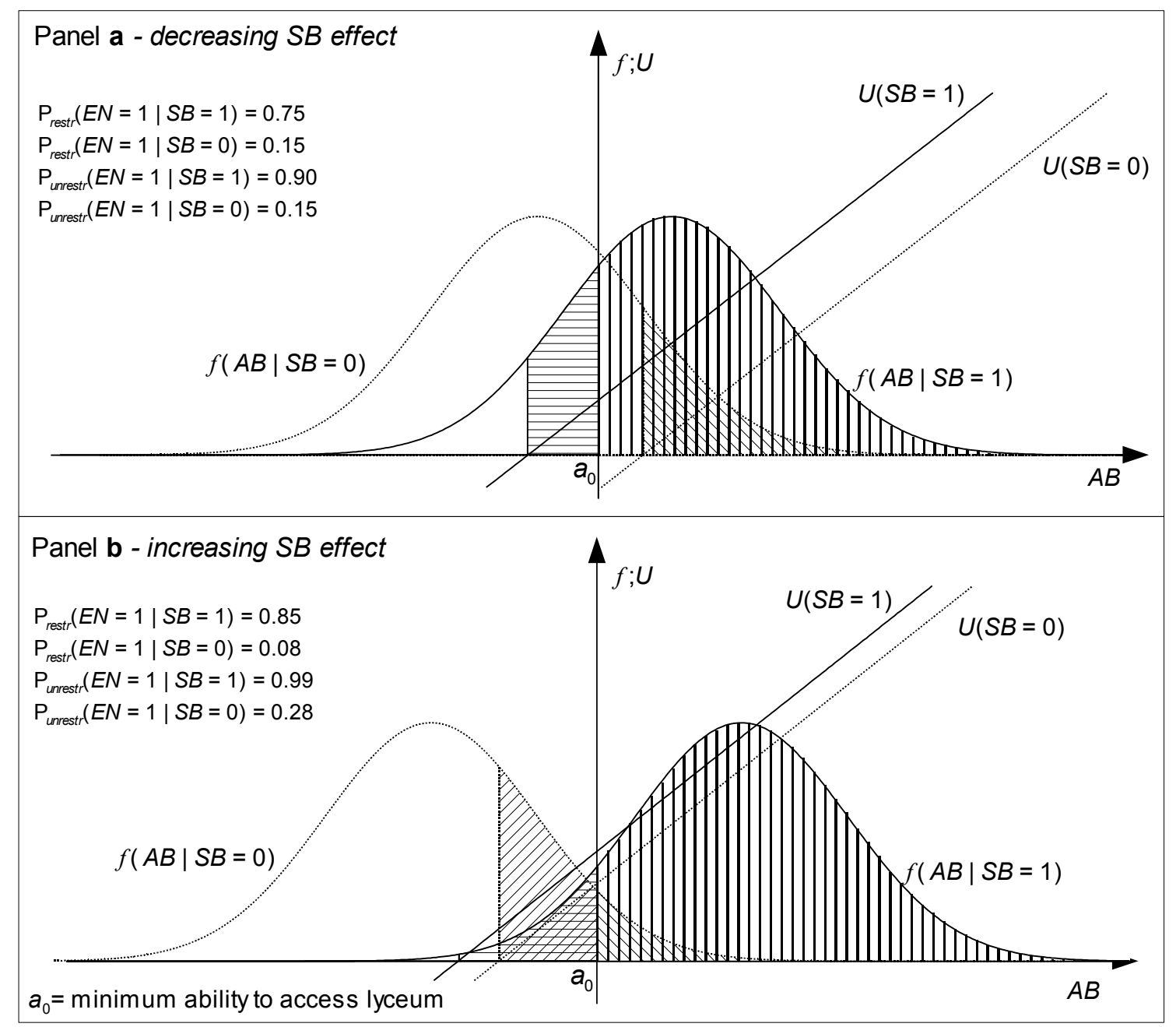

Figure 3. The effect of access restrictions on track enrollment 
Summarising, if access restrictions are at work, ability affects both preferences and admittance, while with free choice only preferences are involved. Although the direct effect of social status on enrolment is always reduced with restrictions, the indirect effect driven by the differences in ability across different backgrounds can be magnified. As the graph suggest, the total effect is likely to increase with restrictions if ability differences among social strata are marked while the utility functions are relatively similar.

Looking at the extreme cases can help to clarify the picture.

(i) If $f(A B \mid S B)=f(A B)$, i.e. the ability distribution is the same for all social classes, the area represented by equation (10) is a subset of that in (9), implying a smaller total effect with restrictions. In fact:

$$
\begin{aligned}
& \int_{A B>a_{0}} P(-\mu-\lambda A B-\xi<\varepsilon<-\mu-\lambda A B) f(A B) d A B< \\
& \int_{A B} P(-\mu-\lambda A B-\xi<\varepsilon<-\mu-\lambda A B) f(A B) d A B
\end{aligned}
$$

(ii) The case where $\xi=0$ is not as straightforward, as the total effect may still increase or decrease with restrictions. Yet, note that if all social background shared the same utility function, the low and the high status would have the same preferences for lyceum given ability. Other things being equal, a larger fraction of the low status would be excluded from enrolling to lyceum with restrictions when compared to the case where the low status have a weaker desire to follow an academic educational programme. Thus, this case is the most "favourable" case for an increasing total effect.

Note that the above discussion holds ceteris paribus. One underlying assumption is that preferences do not change: this may not be a sensible hypothesis if, as lyceum becomes more selective, the degree acquires value with restrictions. Another assumption which may not hold is the invariance of the relation between social background and ability. Anticipatory effects are likely to be strengthened: high status parents in particular may be encouraged to provide 
more support for their children in order to make admission to lyceum more likely, increasing the social background differential in the probability of enrollment into the academic track.

\section{The empirical analysis}

A logistic regression model for track enrollment is estimated for the each country ${ }^{16}$. The empirical analysis is carried out with data from PISA 2003. The Italian sample size is 11.639, including the oversampling requested by local authorities in some regions ${ }^{17}$. The available German sample comprises 4.660 students, since units due to local oversampling are not included, while the Dutch sample is represented by 3.992 units. Students report the type of the school they are currently enrolled in, according to the institutional designs at work in the countries under study. Since it is difficult to find a comparable classification among academic, technical and vocational schools across countries and German Länder, we focus on the distinction between the academic track (lyceum) and all other tracks. The dependent variable is dichotomous, distinguishing Liceo (Italy) ${ }^{18}$, Gymnasium (Germany) and VWO (Netherlands) from all other school types.

Social background $S B$ is measured by the Index of Economic, Social and Cultural Status as defined by PISA. ESCS is a second level continuos index based on three first level indexes, regarding parent's professional status, their education and household possessions related to culture and technology (e.g. books, PCs). The score is the first principal component in the analysis of the three lower level indexes, standardized with respect to OECD average. This index has the advantage with respect to discrete measures of parental education or occupational status that different aspects of social status are taken into account.

We allow for gender, immigrant status and family type differences, by including in the model the following control variables: GENDER (1=female, $0=$ male), FOREIGN (1=nonnative or first-generation student, 0=other), FAMILY ("standard family": 1=father and 
mother living together with student, $0=$ other). Moreover, in order to test whether the social origins effect varies with demographic characteristics, interactions of these variables with ESCS were also included. Geographical differences are marked both in Italy and in Germany. A set of dummy variables (North East, Centre, South) are included for Italy (the reference category being North West), while the binary variable $E A S T^{19}$ distinguishes between states of the former East and West Germany.

The evaluation of the impact of access restrictions is based on Germany. Although institutional and environmental differences do exist across German Länder, they are likely to be weaker than those existing across nations. The explanatory variable RESTRICT (assuming value 1 for states where access to Gymnasium and Realschule is based on ability assessments and 0 elsewhere) and the interaction between this variabile and the ESCS index were included in the German model ${ }^{20}$. Under the assumption that the policy is exogenous and that no unobservables affecting the outcome are correlated with the other explanatory variables, the interaction coefficient gives the impact of the policy on inequality of opportunity. A few other variables capturing institutional differences across the country (see Section 2) where included in the specification but did not prove significant: notably, a binary variable indicating the states where Hauptschule and Realschule are combined together, and a binary variable indicating the states with comprehensive schools.

Since the interest here lies in the total effect of social origins on school choices, as we have argued before, ability is not taken under control. Moreover, PISA does not report adequate measures of ability before school choice is undertaken; the indicator of grade repetitions, referring only to the most severe situations, is a very rough measure, unable to capture the variability in the ability distribution (repetitions before age 14 are very unusual in Italy); the math mark in the last school report, referring to a few months only before the survey was carried out, is only slightly less endogenous than the PISA score. 


\subsection{Results}

Parameter estimates and ASE for the social status index ESCS are reported in Table 2. Since PISA is based on a two stage sampling scheme ${ }^{21}$, observations are correlated. Standard errors are underestimated when assuming independence; they can instead be consistently estimated with re-sampling procedures (as suggested by PISA analysts, we implemented the modified BRR-Balanced Repeated Replication ${ }^{22}$ method).

Nor surprisingly, the ESCS coefficients are significant in all countries: according to the estimates, a unit increase in the index (representing a one standard deviation increase of the variable at the OECD level) leads to a 3-4 times increase in the odds of enrolling into a lyceum: recall however that these values must be taken with caution, as they are biased by unobserved heterogeneity. Italy exhibits the smallest value, followed by Netherlands, and then Germany. The coefficient of the interaction between ESCS and RESTRICT in the German model is negative and significant, thus the social status effect should be weaker in the states with access restrictions. The interaction between ESCS and GENDER in the Italian model suggests that the social origin effect should be stronger for males than for females.

The $A S E$ value, the average partial derivative with respect to social origin across sample units (which is instead nearly unbiased with independent unobserved heterogeneity) can be interpreted as follows: a unit increase in the ESCS index leads to an approximate average net increase in the probability of enrolling into the academic track of 0.188 in Italy, 0.166 in Netherlands, 0.209 in the restricted German states and 0.228 in the unrestricted German states. 
Table 2. Estimation results. Modelling ST for the three countries

\begin{tabular}{|c|c|c|c|c|c|c|}
\hline \multicolumn{7}{|c|}{ ITALY } \\
\hline & $\beta$ & $e^{\beta}$ & $\sigma_{\beta}$ & $\beta$ & $e^{\beta}$ & $\sigma_{\beta}$ \\
\hline Constant & $-1.470 * *$ & 0.230 & 0.145 & $-1.531 * *$ & 0.216 & 0.151 \\
\hline ESCS & $1.118^{* *}$ & $\mathbf{3 . 0 5 8}$ & 0.075 & $1.304 * *$ & 3.685 & 0.0 \\
\hline Female & $0.473 * *$ & 1.604 & 0.135 & $0.551^{* *}$ & 1.734 & 0.134 \\
\hline ESCS * Female & & & & $-0.322 * *$ & 0.724 & 0.114 \\
\hline Foreign born (or parents) & $-0.691 * *$ & 0.501 & 0.324 & $-0.682 * *$ & 0.506 & 0.324 \\
\hline Standard family & $0.224 * *$ & 1.252 & 0.101 & $0.219 * *$ & 1.245 & 0.101 \\
\hline North-East & $-0.423 *$ & 0.655 & 0.218 & $-0.42 * *$ & 0.657 & 0.211 \\
\hline Center & $0.322^{* *}$ & 1.381 & 0.139 & $0.328^{* *}$ & 1.389 & 0.140 \\
\hline South \& Isles & 0.348 & 1.416 & 0.229 & 0.344 & 1.411 & 0.229 \\
\hline \multicolumn{4}{|c|}{$\begin{array}{l}A S E_{E S C S}=0.188 \\
\text { Wald test }=389.1\end{array}$} & \multicolumn{3}{|c|}{$\begin{array}{r}A S E_{E S C S}(\text { male })=0.195 ; A S E_{E S C S}(\text { fem })=0.182 \\
\text { Wald test }=480.4\end{array}$} \\
\hline
\end{tabular}

\begin{tabular}{|l|c|c|c|}
\hline \multicolumn{2}{|c}{} & \multicolumn{2}{c|}{ GERMANY } \\
\hline & $\beta$ & $e^{\beta}$ & $\sigma_{\beta}$ \\
\hline Constant & $-1.756^{* *}$ & 0.1727 & 0.167 \\
\hline ESCS & $\mathbf{1 . 4 1 3 * *}$ & $\mathbf{4 . 1 0 7 9}$ & $\mathbf{0 . 0 8 8}$ \\
\hline ESCS*RESTRICT & $\mathbf{- 0 . 1 9 3}$ & $\mathbf{0 . 8 2 4 7}$ & 0.133 \\
\hline Female & $0.477^{* *}$ & 1.6119 & 0.104 \\
\hline Foreign born (or parents) & -0.151 & 0.8596 & 0.204 \\
\hline Standard family & 170 & 1.1854 & 0.11 \\
\hline East German state & 0.351 & 1.4202 & 0.246 \\
\hline RIGID & 0.104 & 1.1098 & 0.183 \\
\hline
\end{tabular}

\begin{tabular}{|c|c|c|}
\hline$\beta$ & $e^{\beta}$ & $\sigma_{\beta}$ \\
\hline$-1.794^{* *}$ & 0.1663 & 0.167 \\
\hline $\mathbf{1 . 4 3 1}^{* *}$ & $\mathbf{4 . 1 8 2 7}$ & $\mathbf{0 . 0 8 7}$ \\
\hline $\mathbf{- 0 . 2 4 9}^{* *}$ & $\mathbf{0 . 7 7 9 3}$ & 130 \\
\hline $0.469^{* *}$ & 1.5988 & 0.102 \\
\hline & & \\
\hline $0.188^{*}$ & 1.2074 & 0.109 \\
\hline 0.369 & 1.4468 & 0.246 \\
\hline 0.137 & 1.1467 & 0.182 \\
\hline
\end{tabular}

$A S E_{E S C S}($ restrict $)=0.214 A S E_{E S C S}(N O$ restrict $)=0.228$ Wald test $=456.5$

$A S E_{E S C S}($ restrict $)=0.209$ $A S E_{\text {ESCS }}($ NO restr. $)=0.228$ Wald test $=441.7$

\begin{tabular}{|c|c|c|c|}
\hline \multicolumn{4}{|c|}{ NETHERLANDS } \\
\hline & $\beta$ & $e^{\beta}$ & $\sigma_{\beta}$ \\
\hline Constant & $-2.404 * *$ & 0.090 & 0.141 \\
\hline ESCS & $1.176 * *$ & 3.243 & 0.086 \\
\hline Female & $0.191 *$ & 1.211 & 0.104 \\
\hline Foreign born (or parents) & -0.004 & 0.996 & 230 \\
\hline Standard family & $0.715 * *$ & 2.045 & 0.125 \\
\hline \multicolumn{2}{|c|}{$A S E_{E S C S}=0.166$} & \multicolumn{2}{|c|}{ Wald test $=223.0$} \\
\hline
\end{tabular}

$* 0,05<P<0,10 ; * * P<0,05$ assuming approximated normality of parameter estimates.

Figure 4 illustrates the approximate sampling distributions of $A S E$ (estimated with $B R R^{23}$ ) for each country; two distributions are evaluated within Germany, one for states with and one for the states without access restrictions. The estimated distributions display very limited overlapping; according to the $A S E$, the social background effect is lowest in the Netherlands, followed by Italy, then the German states with access restrictions, and lastly the German states without restrictions. The statistical significance of the difference between the nearest 
$A S E$ estimates was evaluated under the assumption (supported by normality tests) of a normal distribution of $A S E$ maximum-likelihood estimates across replicates. The following $p$-values were obtained: 0.017 for the difference between Italy and the Netherlands, 0.040 for the difference between Germany-with restrictions and Italy, 0.049 for the difference between Germany-with restrictions and Germany-without restrictions. The significant difference within Germany provides evidence that the influence of social origins on school track enrolment is weaker with access restrictions.

Notice that the parameter estimates in Table 3 and $A S E$ display an inconsistent ordering: when comparing Italy and Netherlands, the ASE is larger for Italy, whereas the ESCS coefficient estimate is larger for Netherlands. The results are consistent with the theoretical arguments presented in Section 5.1, according to which logistic regression coefficients may have an ambiguous meaning with unobserved heterogeneity.

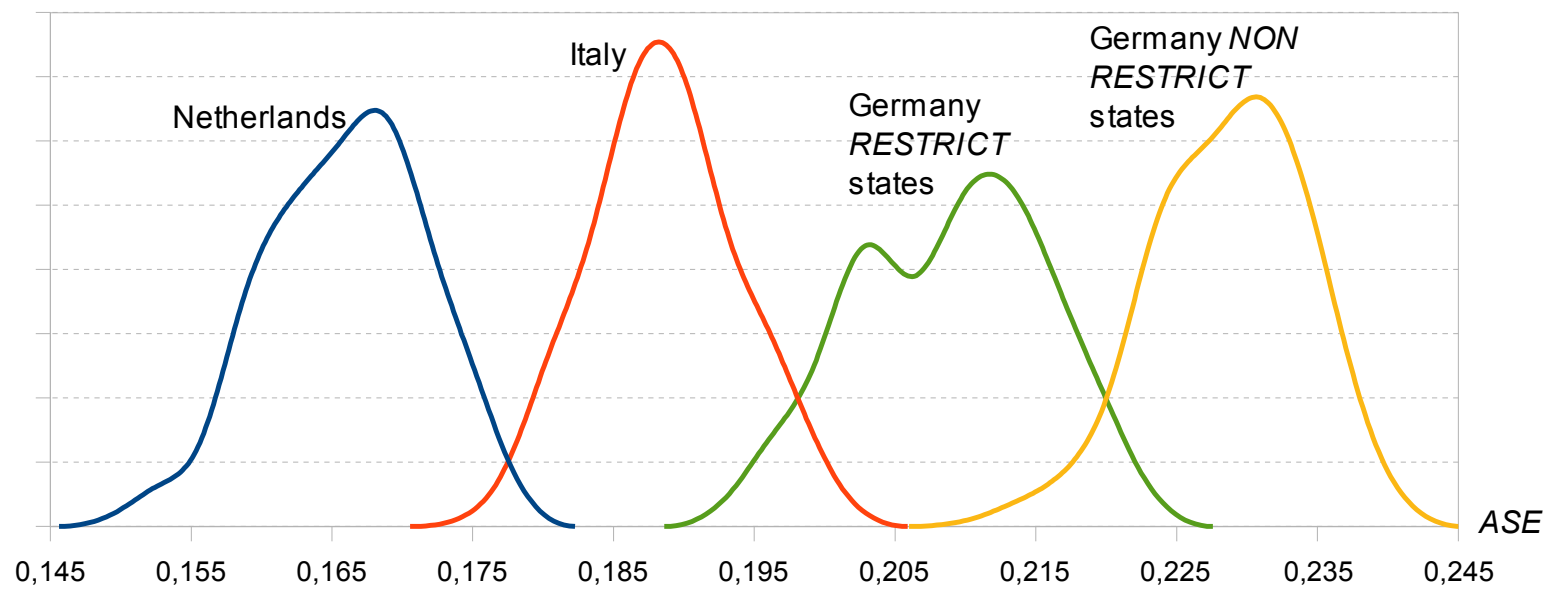

Figure 4. $S B$ total effect ASE - estimated distribution (via Fay-BRR) in each country

\section{Summary and discussion}

In the present work we measure the effect of social origins on the choice of secondary school track for Italy, the Netherlands and Germany allowing for consistent cross-country 
comparisons, by employing PISA 2003. We evaluate the total effect of social origins on secondary school choices, which includes the direct effect of family background and the indirect effect via previous school performance.

Since no adequate measure of performance before tracking is available, ability is not kept under control. Consequently, the adequacy of logistic regression coefficients for crosscountry comparisons in this context is discussed. The literature highlights that with independent unobserved heterogeneity estimates are biased towards zero; we show that when neglecting ability (which is not independent of social background) we can still refer to the independent heterogeneity framework if the total effect is the parameter of interest. Since the bias depends on the variance of the omitted variable, it may considerably differ across countries, thus, comparing the regression coefficients can be misleading.

On the other hand, the average sample derivative (ASE) - measuring the slope of the response probability function where explanatory variables are actually located in the sample is often employed in the literature and is shown by Cramer (2005) to be robust to the omission of independent neglected heterogeneity in simple models. In order to extend these conclusions to our more complex model, we implement a simulation exercise where we show that the omission of previous ability does not substantially affect the relevant $A S E$. This implies that the $A S E$ can be employed to compare the social origin effect in the present context.

The impact of ability-based access restrictions to secondary school tracks on inequality of opportunity is also analyzed. First, we propose a simple theoretical model, and we derive that restrictions should lower the effect of social origins conditional on ability, but the impact on the total effect can go in both directions. Second, by exploiting the institutional differences across Länder with respect to enrolment policies, we carry out a preliminary empirical analysis on this issue within Germany. The main empirical findings are that the total effect of social origins on track choice is weaker in the Netherlands and stronger in Germany, with 
Italy in between and that, within Germany, parental background appears to be less important where access is regulated by ability assessments.

Thus, access restrictions seem to foster equality of opportunity with respect to how individuals of different social origins are sorted into the different tracks. However, this result should be interpreted with caution. The empirical analysis developed in this paper is based on a very simple model: the causal effect of access restrictions is correctly identified if institutional and labor market differences across German states are adequately kept under control. The identifying assumption is that the counterfactual (i.e., the value of the outcome here, a measure of inequality of opportunity - that we would observe in the states with restrictions if restrictions were not at work) is correctly represented by what happens in the states with no restrictions. This is quite a strong claim: for example, if states enforcing and not enforcing enrolment policies were subject to different market conditions, we could get a biased assessment of the impact of the policy.

Secondly, the empirical analysis lacks external validity, and thus the results cannot be extended out of Germany. As the theoretical model developed in Section 6 suggests, the total effect of social background can either increase or decrease with access restrictions: if admission rules interact with other features of the educational system, different effects are possible. For example, inequality appears to be stronger in Germany than in Italy (where access is free) and the Netherlands (where access is also regulated), even in those Länder where these restrictions are at work; these results suggest that admission rules alone do not necessarily counterbalance the negative effects on equality of opportunity due to other features of the school design.

According to our theoretical model, the effect of parental background on secondary school choices given ability is reduced with performance-based restrictions; the role of social origins in shaping preferences is weakened if we focus on enrolment. In fact, at all ability levels the 
probability of having a preference for lyceum is higher for the higher status, also when ability is below the admission threshold. Since restrictions inhibit the enrolment of the low performing students, a larger share of the higher status will be denied access to lyceum with respect to the lower status. On the other hand, we show that the total effect of parental background on enrolment can decrease but can also rise with restrictions. Note that these results are based on the ceteris paribus assumption. This assumption may however be too restrictive: (i) the value attached to the different tracks is likely to change as the system becomes more meritocratic; (ii) anticipatory effects (parents of low performing children giving additional support to their offspring's learning in order to avoid later exclusion from the academic track) could be enhanced with ability restrictions, especially for the higher status, pushing up school performance differentials and consequently the total effect.

Concluding, we think that there is scope for more theoretical and empirical research on the impact of access restrictions. In order to shed light on the mechanisms at work it would be of interest to derive the structural parameters of the model, yet, since information on both individual preferences and actual enrollment is required, this is not an easy task to accomplish at the moment.

\section{Appendix - The simulation study}

The aim of the simulation study is to investigate the behaviour of the logistic regression coefficients in the track choice model, when previous ability is omitted; to assess use of $A S E$, (and ESA) to interpret the effects of explanatory variables in the above context; to evaluate the inclusion of PISA scores as a proxy of students' unobserved ability before choice. We strictly stick to the model in Section 4 , and fix the parameters by referring to real data ${ }^{24}$ whenever possible. We generate data for a continuos variable $S B$ (similar to ESCS in PISA), and for previous ability $A B_{1}$, track choice $T C$, ability after tracking $A B_{2}$. 


\section{A.1 - The simulation model}

35 independent samples of size $n=1000$ are generated for each simulation of the model defined in equations (1)-(3). Since the ESCS empirical distribution in the Italian sample is nearly normal, $S B$ is randomly generated from a normal distribution with the ESCS observed mean and variance. Previous ability $A B_{1}$ is generated according to equation (1), where the values of $\gamma$ and the error variance are equal to the corresponding estimates of a comparable regression of PIRLS 2001 performance scores (PIRLS-Progress in International Reading and Literacy Study is an international assessment similar to PISA carried out on $4^{\text {th }}$ graders). School track $T C$ is generated as in $(2 a)-(2 b)$. This is the equation of main interest: by considering various pairs of ability $(\lambda)$ and social background $(\xi)$ coefficients, we are able to assess the behaviour of the estimates in different situations. For each set of values $(\lambda ; \xi), \mu$ is adjusted in order to get percentages of individuals in each track as close as possible to the observed distribution. Ability after tracking $A B_{2}$ is generated as in (3) with a normally distributed error; the regression coefficients estimates of the model for PISA scores on $S B$ and $T C$ are taken, while the unknown $A B_{1}$ coefficient is fixed arbitrarily, but at a "reasonable" level.

A logistic regression for $T C$ is then estimated for each of the 35 replicated samples with the following explanatory variables: (i) $A B_{1}$ and $S B$ (full model), as a reference point; (ii) $S B$ only (reduced model), to study how the estimate of the social background total effect $(\xi+\lambda \gamma)$ on track choice is affected by omission of previous ability; (iii) $S B$ and $A B_{2}$, to assess how the inclusion of PISA scores as a proxy of previous ability (as done in Schnepf, 2002 and in Checchi and Flabbi, 2007) biases the estimate of $\xi$ and $\lambda$. Logit regression coefficients, $A S E$ and ESA associated to the total effect of social origins, together with their standard errors are computed for every full and reduced model. 


\section{A2. When previous ability is omitted}

The results of the simulation study are summarised in Table 3. Columns (1)-(4) report the values of the parameters generating the data, while columns (5)-(8) refer to the results of the simulations: the average values and standard deviations of the estimates of the total effect across replications. The higher panel refers to a set of simulations where the values of $\xi$ and $\lambda$ give rise to an estimated total effect close to the actual estimate for Italy 1.118 (see Section 7.1). The true value of $(\xi+\lambda \gamma)$ is often much higher than the corresponding estimate. In the lower panel we consider cases with $\gamma=0$, where the omitted variable is uncorrelated with included regressors. Here the true effect is set to 1.118; again, the estimated coefficients are much smaller. These results altogether demonstrate that logit regression coefficients are heavily downward biased, even when the omitted variable is uncorrelated with the included regressors. The average values across replications of $A S E$ under the full model (correctly including $S B$ and previous ability) are reported in column (6); these estimates are unbiased and thus are taken as a reference point in column (7), where the ratio of the estimated $A S E$ for the reduced and the full model is shown. Column (8) refers to the same ratio for ESA. Whereas $E S A$ varies considerably from full to reduced model, the $A S E$ ratio is always very close to 1 and standard deviations are generally small. Such results strongly suggest that $A S E$ is a more reliable measure of the effect of covariates on binary response variables than logit regression coefficients ${ }^{25}$, and it is thus more suitable for cross-country comparisons in the context under study. 
Table 3. Estimated, true total effect parameters, ASE, ASE and ESA ratios for reduced models

\begin{tabular}{|c|c|c|c||c|c|c|c|}
\hline$(1)$ & $(2)$ & $(3)$ & $(4)$ & $(5)$ & $(6)$ & $(7)$ & $(8)$ \\
$\lambda$ & $\xi$ & $\gamma$ & $\xi+\lambda \gamma$ & $\widehat{\xi+\lambda \gamma}$ & $A S E_{E S C S}^{F}$ & $A S E_{E S C S}^{R} / A S E_{E S C S}^{F}$ & $E S A_{E S C S}^{R} / E S A_{E S C S}^{F}$ \\
\hline 0.064 & 1.400 & 25 & 3.000 & $1.188(0.084)$ & $0.198(0.011)$ & $1.017(0.068)$ & 1.195 \\
\hline 0.044 & 1.000 & 25 & 2.000 & $1.092(0.072)$ & $0.197(0.018)$ & $0.989(0.068)$ & 0.909 \\
\hline 0.034 & 0.950 & 25 & 1.650 & $1.102(0.071)$ & $0.175(0.008)$ & $0.998(0.048)$ & 0.945 \\
\hline 0.024 & 0.900 & 25 & 1.500 & $1.084(0.091)$ & $0.197(0.010)$ & $0.988(0.036)$ & 0.833 \\
\hline 0.014 & 0.900 & 25 & 1.400 & $1.123(0.093)$ & $0.198(0.010)$ & $1.002(0.028)$ & 0.960 \\
\hline 0.004 & 1.050 & 25 & 1.200 & $1.130(0.077)$ & $0.202(0.013)$ & $1.002(0.008)$ & 1.008 \\
\hline 0.014 & 1.118 & 0 & 1.118 & $0.962(0.088)$ & $0.176(0.013)$ & $0.999(0.025)$ & 0.950 \\
\hline 0.024 & 1.118 & 0 & 1.118 & $0.783(0.087)$ & $0.156(0.009)$ & $0.977(0.049)$ & 0.805 \\
\hline 0.034 & 1.118 & 0 & 1.118 & $0.666(0.071)$ & $0.124(0.010)$ & $0.997(0.069)$ & 0.908 \\
\hline 0.044 & 1.118 & 0 & 1.118 & $0.538(0.068)$ & $0.106(0.011)$ & $1.008(0.085)$ & 0.872 \\
\hline 0.064 & 1.118 & 0 & 1.118 & $0.436(0.074)$ & $0.086(0.008)$ & $1.018(0.131)$ & 1.162 \\
\hline 0.084 & 1.118 & 0 & 1.118 & $0.312(0.065)$ & $0.064(0.010)$ & $1.046(0.179)$ & 1.162 \\
\hline
\end{tabular}

* Columns 5, 6, 7 and 8 show averages over the replicated simulations (standard errors in parentheses)

\section{A3. Employing PISA scores to proxy ability}

All simulations carried out show that including PISA scores $A B_{2}$ as a proxy for previous ability $A B_{1}$ can have dramatic consequences. Regression coefficients $\xi$ and $\lambda$ are heavily biased; the direction of the bias varies across simulations depending on the other parameters values. Examples of situations with bias in different directions are reported in Table 4. The estimate of $\xi$ can even become negative in some cases (see column 3), implying that a higher social origins would lower the probability to enrol to the academic track. Notice that results can be very misleading even when the track has a weak influence on $A B_{2}$ (small $\delta^{\prime}$, mimicking for example situations where the timespan between tracking and the PISA survey is small). 
Table 4. Different bias configurations when using $A B_{2}$ (PISA scores) in logistic models for SC

\begin{tabular}{|c|c|c|c|c|c|}
\hline & & $\begin{array}{c}\hat{\xi}, \hat{\lambda} \text { both } \\
\text { biased downward }\end{array}$ & $\begin{array}{c}\hat{\xi}, \hat{\lambda} \text { both } \\
\text { biased } \boldsymbol{u p w a r d}\end{array}$ & $\begin{array}{c}(3) \\
\hat{\xi} \text { biased downward } \\
\hat{\lambda} \text { biased } \boldsymbol{u p w a r d}\end{array}$ & $\begin{array}{c}\hat{\lambda} \text { biased downward } \\
\hat{\xi} \text { biased upward }\end{array}$ \\
\hline \multirow{6}{*}{ 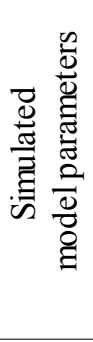 } & $\xi$ & 0.399 & 0.764 & 0.764 & 0.028 \\
\hline & $\lambda$ & 0.028 & 0.028 & 0.028 & 0.044 \\
\hline & $\gamma$ & 37 & 25 & 25 & 25 \\
\hline & $\beta^{\prime}$ & 0.5 & 0.5 & 0.5 & 0.5 \\
\hline & $\gamma^{\prime}$ & 23 & 0 & 50 & 20 \\
\hline & $\delta^{\prime}$ & 82 & 200 & 200 & 45 \\
\hline \multirow{4}{*}{ 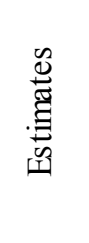 } & $\mathrm{E}(\hat{\xi})$ & 0.355 & 0.843 & -0.846 & 0.260 \\
\hline & $\sigma(\hat{\xi})$ & 0.108 & 0.173 & 0.222 & 0.074 \\
\hline & $\mathrm{E}(\hat{\lambda})$ & 0.020 & 0.034 & 0.034 & 0.013 \\
\hline & $\sigma(\hat{\lambda})$ & 0.001 & 0.003 & 0.003 & 0.001 \\
\hline
\end{tabular}

\section{Acknowledgments}

We wish to thank Robert Erikson and Michelle Jackson for their helpful comments.

\section{References}

Breen R., Goldthorpe J. H. (1997) Explaining educational differentials. Towards a formal rational action theory, Rationality and Society, Vol 9(3), 275-305

Breen R., Jonsson J.O. (2005) Inequality of opportunity in comparative perspective: recent research on educational attainment and social mobility, Annual Review of Sociology 31: 223-243.

Breen R., Luijkx R., Muller W., Pollak R. (2005) Non-persistent inequality in educational attainment: evidence from eight European countries, EQUALSOC paper, Manneheim, 23 December 2005

Boudon R. (1974), Education, Opportunity and Social Inequality. New York, Wiley

Brunello G., Checchi D. (2007) Does school tracking affect equality of opportunity? New international evidence, Economic Policy, 52

Hannum E., Buchman C. (2003) The consequences od global educational expansion, Occasional paper of the American Academy of Arts and Sciences, Cambridge, MA 
Cappellari L. (2004) High School types, academic performance and early labour market outcomes, IZA Discussion Paper n. 1048

Carneiro P., Heckman J. (2003) Human capital policy, NBER WP 9495, http://www.nber.org/ papers/w9495

Checchi D. (2008) Il passaggio dalla scuola media alla scuola superiore, rapporto a INVALSI, mimeo, (in Italian), http://checchi.economia.unimi.it/pdf/un48.pdf

Checchi D., Flabbi L. (2006) Mobilità intergenerazionale e decisioni scolastiche in Italia, in Ballarino G. and Checchi D., Sistema scolastico e disuguaglianza sociale. Scelte individuali e vincoli strutturali, Il Mulino, Studi e Ricerche.

Checchi D., Flabbi L. (2007) Intergenerational mobility and schooling decisions in Germany and Italy: the impact of secondary school tracks, IZA Discussion Paper 2876

Cramer J.S. (2005) Omitted variables and mis-specified disturbances in the logit model. Tinberg Institute Discussion Paper TI 2005-084/4, University of Amsterdam

Dustmann (2001) Parental background, primary to secondary school transitions, and wages, IZA Discussion Paper n. 367

Erikson R., Goldthorpe J. H. (2002) Intergenerational inequality: a sociological perspective, Journal of Economic Perspectives, vol 16, n. 3

Erikson R., Goldthorpe J. H., Jackson M., Yaish M., Cox D. R. (2005) On class differentials in educational attainment, Proceedings of the National Academy of Sciences, vol. 102, n. 27, 9730-9733

Eurydice, German Unit (2006a) Eurybase the Information Database on Education Systems in Europe,The Education System in Germany 2004/2005, http:// www.eurydice.org

Eurydice, Italian Unit (2006b) Eurybase the Information Database on Education Systems in Europe,The Education System in Italy 2005/2006, http://www.eurydice.org

Eurydice, Nederland (2006c) Eurybase the Information Database on Education Systems in Europe, Organisation of the education system in the Netherlands 2005/2006, http://www.eurydice.org

Eurydice Nederland (2003) Structures of education, vocational training and adult education systems in Europe,The Netherlands 2003,http:// www.eurydice.org 
Goldthorpe J.H. (1996) Class analysis and the reorientation of class theory: the case of persisting differentials in educational attainment, British Journal of Sociology, 45(3): 481-506

Hanushek E. A., Woessman L. (2005) Does educational tracking affect performance and inequality? Difference-in-differences evidence across countries, IZA Discussion Paper $n$. 1901

Jackson M., Erikson R., Goldthorpe J.H., Yaish M. (2007) Primary and Secondary Effects in Class Differentials in Educational Attainment: the Transition to A-Level Courses in England and Wales, Acta Sociologica, 50(3), 211-229

Kultusministerkonferenz-KMK(2006) Übergang von den Grundschulen in Schulen des Sekundarbereichs I, http://www.kmk.org/doc/pibl/ueberg.pdf

Long J. S. (1997) Regression Models for Categorical and Limited Dependent Variables Advanced Quantitative Techniques in the Social Sciences Number 7. Sage Publications: Thousand Oaks, CA.

OECD (2004) Learning for Tomorrow's World. First Results from PISA 2003.

OECD (2005) PISA 2003 Technical report

Pfeffer F. T. (2008), Persistent Inequality in Educational Attainment and its Institutional Context, European Sociological Review, advance online access

Prenzel M., Baumert J., Blum W., Lehmann R., Leutner D., Neubrand M., Pekrun R., Rost J., Schiefele U. (2005) PISA 2003: Ergebnisse des zweiten Ländervergleichs Zusammenfassung, http://www.ipn.uni-kiel.de/aktuell/publikationen.html

Schnepf S. V. (2002), A sorting hat that fails? The transition from primary to secondary school in Germany, Innocenti Working Papers n. 92, Innocenti Research Centre, UNICEF

Sinn H. W. (2006) PISA and the German three-class society, The IFO Viewpoint, Institute for Economic Research, University of Munich

Shavit Y., Blossfeld, H.P. (1993) (eds.) Persistent inequality: changing Educational attainment in thirteen countries, Westview, Boulder, Colorado

Wooldridge J. M. (2002) Econometric Analysis of Cross section and Panel Data, MIT Press, Cambridge, Massachusetts

Woessmann L. (2007) Fundamental Determinants of School Efficiency and Equity: German States as a Microcosm for OECD Countries, CESifo Working Paper 1981 


\section{NOTES}

1 Trends in International Mathematics and Science Study (TIMSS), International Adult Literacy Survey (IALS).

2 The survey Percorsi di Studio e Lavoro dei Diplomati (ISTAT 1998, 2001, 2004, 2007) is specifically designed to investigate the tertiary education and working careers of selected cohorts of secondary school leavers.

3 Data from household or population surveys is also inadequate because it does not allow to focus on specific cohorts of students (cohort sample sizes are typically too small).

4 Recent research indicates that at least one third of families do not follow the advice offered by the student's teachers at the end lower secondary school (Checchi, 2008).

5 The same approach has been employed by Schnepf (2002).

6 In this light, we will not consider this school type as belonging to the academic track in the empirical analyses.

7 CITO (Central Institute for Test Development), a private enterprise created under the auspices of the Dutch Education Ministry, develops testing tools for the analysis of individual knowledge, skills and competences in a wide variety of contexts. Among them is the End of primary school Test, administered to about $85 \%$ of pupils finishing primary schools in the Netherlands and measuring academic skills in four areas: language, mathematics, study skills and world orientation.

8 Although in some cases the first period at the chosen school is considered a trial period.

9 Baden-Württemberg, Bayern, Saarland, Sachsen and Thüringen (with about 1/3 of the students population) will be classified as states with restricted access policies for 2003 (KMK, 2006) in the empirical analyses.

10 Such as Oberschulen, Sekundarschulen, Erweiterte Realschulen, Mittelschulen, Regelschulen.

11 Although regional differences are marked: performance scores are much higher in the North of the country than in the South.

12 Here the term ability has a somewhat loose meaning, avoiding all controversies about its definition and evaluation, as the structure of the model is unaffected by the particular definition employed (note however that the literature on primary and secondary effects explicitly refers to "demonstrated ability", i.e. the official evaluation of a student's learning advancement, usually grade point average, which is more likely to be involved in the school track decisionmaking process).

13 Let $U_{L}$ being the utility of lyceum and $U_{O}$ the utility of the other school tracks. Individual choose the option with the highest utility. We can think of $U$ as the difference $\left(U_{L}-U_{O}\right)$; lyceum is chosen if $U>0$, other tracks if $U<0$. 


\section{NOTES}

14 If innate ability is genetically transmitted, an intergenerational mechanism of social selection induces some correlation between innate ability and social status, making it impossible to separately identify the effects of "nurture" (which can be targeted by public intervention) and the effects of "nature" (which cannot be targeted by public intervention).

15 Referring to a continuos variable is relevant in this context because in the empirical analysis we employ the continuos variable ESCS (see Section 7); other almost continuos variables measuring occupational prestige (SEI, for example) are sometimes employed as well. Notice however that the discussion also holds for discrete variables; a measure based on average sample probability differences could be employed instead.

16 Strictly speaking, the models are misspecified because of the omission of ability (see Section 5), although consequences are shown to be negligible if $A S E$ is employed as a measure of inequality of opportunity. An additional source of misspecification applies for Netherlands and the restricted German states, where preferences and enrolment do not overlap. In this case the model should be formalised by superimposing condition (7) on the model for track choice and averaging with respect to $A B$ as shown in (8). Unless strong assumptions are made, the structural model cannot be estimated if data on preferences and actual enrollment are not both available. For these reasons, notwithstanding the misspecification, the empirical analysis is based on the simple logistic specification with track enrollment as the dependent variable.

17 Like Piedmont, Tuscany, Veneto, Trentino-Alto Adige.

18 Given the features of the socio-pedagogic-lyceum (see Section 2), we decided not to include it in the academic track. Unfortunately, in the PISA database Italian licei also includes this school type. Given the fact that girls are the large majority of the student in socio-pedagogic schools, distinctly from the other school types, we identified these schools as those with at least $80 \%$ of females (to mirror the proportion reported by the official statistics at a national level).

19 Following Woessmann (2007) the state of Berlin is considered an Eastern German Länder.

20 In PISA 2003 German Länder are not explicitly identified. We have sent a request for this information to the Institute for Educational Progress, Berlin. In the meantime, a first identification is possible because the states have been used as a stratification variable (OECD, 2005). Excluding special education and vocational schools, the remaining 16 strata could be attributed to a Länder, by comparing strata and states with respect to their relative size and the percentage of students enrolled to different school types (official data on school types at the Länder level is 


\section{NOTES}

in Prenzel et al, 2005). For the purpose of this work, this provisional identification was employed only in aggregate form, represented by the variables EAST and RESTRICT described above.

21 Schools are the primary sampling units, chosen with probability proportional to their size; around 30 students are randomly chosen within each school. Weights are adjusted to give each student the same selection probability, considering their school, the oversampling of some strata, school and student non-response and other inaccuracies.

22 BRR is derived from the well-known Jackknife method but uses a more complex scheme of unit removing and reweighting; further stability is added by Fay modification, avoiding the complete removal of units and building each replication using weights.

23 Since only 80 replicated observations are available for each density, the histogram shows rough B-spline smoothing approximations.

24 With reference to PISA 2003 and to the international assessment carried out on $4^{\text {th }}$ graders PIRLS 2001 (Progress in International Reading and Literacy Study).

25 At first sight it may seems strange that the $A S E$ values across the simulations are remarkably close to each other in models with different parameter values. However it must be recalled that $A S E$ and logit regression coefficients measure different aspects of the effect of explanatory variables, and the $A S E$ for a covariate is influenced by both its regression coefficient and the model intercept. Since the constant was here determined in order to keep the marginal distribution of $T C$ as similar as possible to the observed distribution in all simulations, the response probability curves corresponding to higher value of the total effect are steeper in the central part of the distribution of $S B$, but are less steep near the tails. On average, the partial derivatives can indeed be roughly the same across simulations. 